\title{
Increased Vascularization and Heterogeneity of Vascular Structures Occurring in Polyglycolide Matrices Containing Aortic Endothelial Cells Implanted in the Rat
}

\author{
WALTER D. HOLDER, Jr., M.D., ${ }^{1}$ HELEN E. GRUBER, Ph.D., ${ }^{2}$ WENDY D. ROLAND, \\ B.A., ${ }^{1}$ ALECIA L. MOORE, B.S., ' CATHERINE R. CULBERSON, M.S.,1 \\ ANNA B. LOEBSACK, M.S., ${ }^{1}$ KAREN J.L. BURG, Ph.D., ${ }^{1}$ and \\ DA VID J. MOONEY, Ph.D. ${ }^{3}$
}

\begin{abstract}
The development of sufficient vascularization to maintain adequate perfusion is a primary consideration in the engineering of large tissue constructs. This research investigated the ability of aortic endothelial cells to affect the orgamization of vascular structures within a matrix both in vitro and in vivo. Highly porous matrices of poly (glycolic) acid (PGA) $(50 \mathrm{mg} / \mathrm{cc}) 10 \times$ $10 \times 3 \mathrm{~mm}$ meshes were implanted subcutaneously (two per rat) in inbred rats, with and without syngeneic cells. Test groups ( $=8$ /group) were: PGA; PGA with aortic endothelial cells; PGA with aortic smooth muscle cells; PGA with skeletal muscle cells. Matrices were evaluated histologically from two rats per week at weeks $1,2,3$, and 4 . Scanning electron microscopy was done on matrices prior to implantation. Matrices without cells demonstrated typical ingrowth of host fibroblasts, capillaries, and macrophages/giant cells. Matrices contaiming skeletal muscle or aortic smooth muscle cells showed similar vascularization to matrices without cells. The implanted muscle cells demonstrated cellular growth with little organization. Matrices containing aortic endothelial cells demonstrated organized and unorganized endothelial cells within the matrix, increased nunbers of capillaries, increased numbers of lymphatic-like structures, and numerous heterogeneous and unusual vascular structures which were positive for factor VIII localization including: 1) large parallel arrays of capillaries, 2) large thin sinusoidal vascular structures, and 3) layered complex vascular structures.
\end{abstract}

\section{INTRODUCTION}

PPRoximately EIGHT Million SURGiCal PROCEDURES are performed annually in the United States to
treat individuals who have lost tissue or organs as a result of a variety of disease processes and in-
juries. ${ }^{1}$ Organ loss is typically treated by transplantation of organs from one individual to another, ${ }^{2}$ the use

Departments of ${ }^{1}$ General Surgery Research and ${ }^{2}$ Orthopaedic Surgery, Carolinas Medical Center, Charlotte, North Carolina 28232. ${ }^{3}$ Departments of Biologic and Material Sciences and Chemical Engineering, University of Michigan, Ann Arbor, Michigan 48109.

Presented in part at the Inaugural Meeting of the Tissue Engineering Society, Orlando, Florida, December 13-15, 1996. 


\section{HOLDER ET AL.}

of surgical reconstruction techniques, or the use of mechanical devices and prosthetics. Mechanical devices are often less than satisfactory replacements for the lost organ or tissue because many of the characteristic qualities of the tissue cannot be replaced. In addition, many organs have never been successfully transplanted and/or transplantation is impractical or contraindicated because of the need for immunosuppression or related concerns.

Breast and soft tissue reconstruction for cancer, trauma, or for cosmetic purposes has relied primarily on mechanical implants or surgical flap techniques to move tissues to needed locations. The goal of breast and soft tissue reconstruction is to produce a tissue mass with all of the aesthetic properties of natural tissue. Because of the many associated problems with artificial implants, new methods of breast and soft tissue reconstruction are needed.

Tissue engineering is a relatively new discipline that incorporates principles of engineering, chemistry, cell biology, and physiology to produce biological substitutes that restore, maintain, or improve tissue function. ${ }^{3}$ The appeal of tissue engineering is that functional tissue can be reconstructed using either autologous or allogenic cells derived from relatively small tissue biopsies. The ability to expand cells in vitro produces a nearly continuous supply which can be used for the reconstruction of tissues.

A variety of biomaterials have been developed or are being designed for use in tissue engineering. ${ }^{4,5}$ Both natural and synthetic polymers have played an important role in this regard. These materials have been employed in three-dimensional constructs to provide scaffolds for the growth of transplanted cells. ${ }^{4-20}$ Many of these polymers have had particular appeal in that they are hydrolyzed over time and completely disappear without leaving residual substances. Polyesters and co-polyesters of naturally occurring hydroxy acids including glycolic acid, lactic acid, and epsilon caproic acid are widely employed in tissue engineering.

Various constructs of autologous cells and highly porous absorbable polymers show considerable promise for tissue engineering. The development of sufficient vascularization to maintain adequate perfusion of the cells with oxygen and nutrients and to eliminate metabolic products is a primary consideration in the engineering of thicker tissue constructs. The practical thickness of most constructs is severely limited (several millimeters at most) because of the slow ingrowth of host vasculature and resultant limited diffusion of nutrients and oxygen. This invariably leads to the death of many cells that have been seeded into the polymer before implantation. This is a substantial problem for the development of constructs $10 \mathrm{~cm}$ or thicker needed for large tissue defects and most breast reconstruction.

Our laboratories are evaluating a variety of cell and polymer fabrications and techniques for the development of thicker constructs that may be used for tissue-engineered breast reconstruction. The research addresses the hypothesis that the addition of syngeneic vascular endothelial cells to PGA meshes will result in increased vascularization of the mesh when implanted into a host.

\section{MATERIALS AND METHODS}

\section{Protocol}

PGA $(50 \mathrm{mg} / \mathrm{cc}$ ) matrices were implanted subcutaneously (two per rat) on the flanks of 8- to 12 -weekold female Lewis rats. The groups tested were as follows: a) eight received matrices without cells, b) eight received matrices with aortic endothelial cells, c) eight received matrices with aortic smooth muscle cells, and d) eight received PGA matrices with skeletal muscle cells. Animals were euthanized by $\mathrm{CO}_{2}$ overdose, two per week per group at weeks 1,2,3, and 4, and the constructs evaluated histologically for cell growth and characteristics of vascularization. Several cell-containing matrices in each group were evaluated by scanning electron microscopy prior to implantation.

\section{Matrices}

Highly porous ( $>90 \%$ ) matrices of PGA mesh in the form of $10 \times 10 \times 3 \mathrm{~mm}$ wafers were prepared by Albany International (Albany, NY). PGA was composed of a non-woven array of fibers. The bulk density of the PGA was $50 \mathrm{mg} / \mathrm{cc}$. The average diameter of the PGA fibers was 12 microns. This PGA is nonenzymatically hydrolyzed in vitro in approximately 3 months. 


\section{INCREASED VASCULARIZATION AND HETEROGENEITY OF VASCULAR STRUCTURES}

\section{Cell Preparation}

Aortic endothelial, aortic smooth muscle, and skeletal muscle cells were obtained from syngeneic donor rats and established as primary cultures. The aorta was aseptically collected from an euthanized donor rat, stripped of adventitia, and washed three times in Hank's Balanced Salt Solution (Sigma, St. Louis, MO). The aorta was sliced into rings and placed on a $12.5 \mathrm{~cm}^{2}$ flask and placed in a $37^{\circ} \mathrm{C}$ incubator for $45 \mathrm{~min}$ without media. Three $\mathrm{ml}$ of media were carefully placed in the flask without disturbing the tissue. The medium consisted of Dulbecco's Modified Eagle's Medium (DMEM) (Mediatech, Herdon, VA) with the following supplements: $10 \%$ fetal bovine serum (FBS), $0.02 \mu \mathrm{g} / \mathrm{ml}$ basic fibroblastic growth factor, $1 \%$ of penicillin-streptomycin solution, $100 \mathrm{U} / \mathrm{ml}$ nystatin, $5 \mu \mathrm{g} / \mathrm{ml}$ insulin, $5 \mu \mathrm{g} / \mathrm{ml}$ transferrin, and $5 \mathrm{ng} / \mathrm{ml}$ sodium selenite (all Sigma, St. Louis, MO). Colonies of endothelial cells grew from the aortic rings and were subsequently expanded as pure populations of endothelial cells. Skeletal muscle was obtained as a biopsy from the leg or abdomen and prepared in a similar fashion. Aortic smooth muscle cells were obtained by placing aortic rings in $1 \mathrm{mg} / \mathrm{ml}$ collagenase, $0.125 \mathrm{mg} / \mathrm{ml}$ elastase, and $1 \mu \mathrm{l} / \mathrm{ml}$ FBS in $15 \mathrm{ml}$ of DMEM and incubated for $45 \mathrm{~min}$ at $37^{\circ} \mathrm{C}$. The digested tissue was then triturated through a 15 gauge cannula and passed through a $70 \mu \mathrm{m}$ sterile mesh. The cells were plated in Smooth Muscle Growth Medium (Clonetics, San Diego, CA) supplemented with SMGM-2 in Biocoat flasks (Collaborative Laboratories, Bedford, MA). Cell types were confirmed by avidin-biotin antibody labeling with anti-factor VIII (endothelial cells) or anti-desmin (skeletal and smooth muscle cells).

\section{Cell Attachment to Matrices}

Four to six polymers were placed into a $100-\mathrm{ml}$ silicone-coated spinner flask with $30 \mathrm{ml}$ of medium. For each polymer, 2.5 to $5.0 \times 10^{6}$ cells were added to the medium. Viability of cells was determined using trypan blue (Sigma, St. Louis, MO) dye exclusion. In all cases, viability was $99 \%$ or greater. The polymers were stirred for $24 \mathrm{~h}$ in an incubator and then placed into a sterile Petri dish. After the incubation period, cells remaining in the medium were quantitated to estimate the number of cells adhering to the polymer. Cell counts indicated that $97 \%$ of the muscle cells and $75 \%$ of the aortic endothelial cells were adherent to the polymers.

\section{Animals}

Eight- to 12-week-old female, inbred, Lewis rats were obtained from Harlan Sprague Dawley (Indianapolis, IN) and used for the study. Public Health Service and Carolinas Medical Center Institutional Animal Care and Use Committee guidelines were observed. Rats were given standard rat feed and water ad libitum and were on a 12-h light/dark cycle.

\section{Surgical Procedures}

Aseptic technique was used for all surgical procedures. Animals were anesthetized with isoflurane. An area of the back and flank was shaved and prepped with Betadine ${ }^{\mathrm{TM}}$ and $70 \%$ ethanol. For implantation of polymers, two incisions approximately $1 \mathrm{~cm}$ in length were made in either flank. A subcutaneous pocket was then created by blunt dissection about $2 \mathrm{~cm}$ lateral to the mid-line. The polymers were placed underneath the pocket, and the skin was closed with surgical staples. Rats recovering from surgery were warmed with a heating pad and continuously observed until ambulatory and twice daily thereafter. Surgical staples were removed on postoperative day 7 .

\section{Histology}

All rats and histologic preparations were given identification code numbers. A wide block of the skin, matrix, and muscle was excised from euthanized animals. Care was taken to include skin, underlying muscle, and ribs so that the implanted area was not disturbed. The blocks were pinned on a cork sheet and fixed in 10\% neutral buffered formalin for $24 \mathrm{~h}$. The blocks were then sliced perpendicular to the skin surface at 3- to 4-mm intervals to locate the implanted matrix. The implant and adjacent tissue were then oriented and placed in a processing cassette, taken through a graded ethanol series, and embedded in paraffin using a 
Shandon Lipshaw ${ }^{\mathrm{TM}}$ automatic paraffin processor. Each piece of tissue was oriented and embedded on edge for a complete cross-sectional view. A Leica 2065 microtome was used for sectioning. Sections were deparaffinized and stained with hematoxylin and eosin or Masson's trichrome, and permanently mounted with Permount (Fisher, Pittsburgh, PA). The presence and distribution of endothelial cells was confirmed by avidin-biotin antibody labeling with anti-factor VIII (Sigma, St. Louis, MO). Microvessels were quantitated using the method of Weidner et al. ${ }^{21}$ Capillaries and other microvessels were localized by factor VIII staining and counted as microvessels $/ \mathrm{mm}^{2}$ within the PGA matrices. Quantitative analysis was performed with OsteoMetrics software. The mean area of tissue scored was $2.43 \mathrm{~mm}^{2} \pm 0.56$ for each sample.

Histologic slides were evaluated by two of the investigators for cell growth and vascularization. Multiple photographs were taken of each matrix and surrounding tissues in each of the experimental animals using a Zeiss microscope with a Nikon camera and video camera film.

\section{Scanning Electron Microscopy (SEM)}

Samples were placed in $1 \%$ glutaraldehyde for $1 \mathrm{~h}$ and transferred to $0.1 \%$ formaldehyde for $24 \mathrm{~h}$. The matrix samples were then stored in a phosphate buffered saline solution and later dehydrated through a series of graded ethanol solutions. Matrices were attached to aluminum mounts with conductive glue and sputter coated with gold using a Polaron Model 5100 Sputter Coater. Micrographs were obtained with an ISI DS-130 scanning electron microscope. Magnification and voltage values were placed on the respective photographs.

\section{RESULTS}

\section{SEM of Matrices}

Figure 1 shows SEM images of a PGA matrix with aortic endothelial cells as it would appear immediately before implantation into a rat. The matrices consistently showed scattered cells and cell clusters attached to the matrix. This also was a consistent observation with both the vascular smooth muscle and skeletal muscle (data not shown).

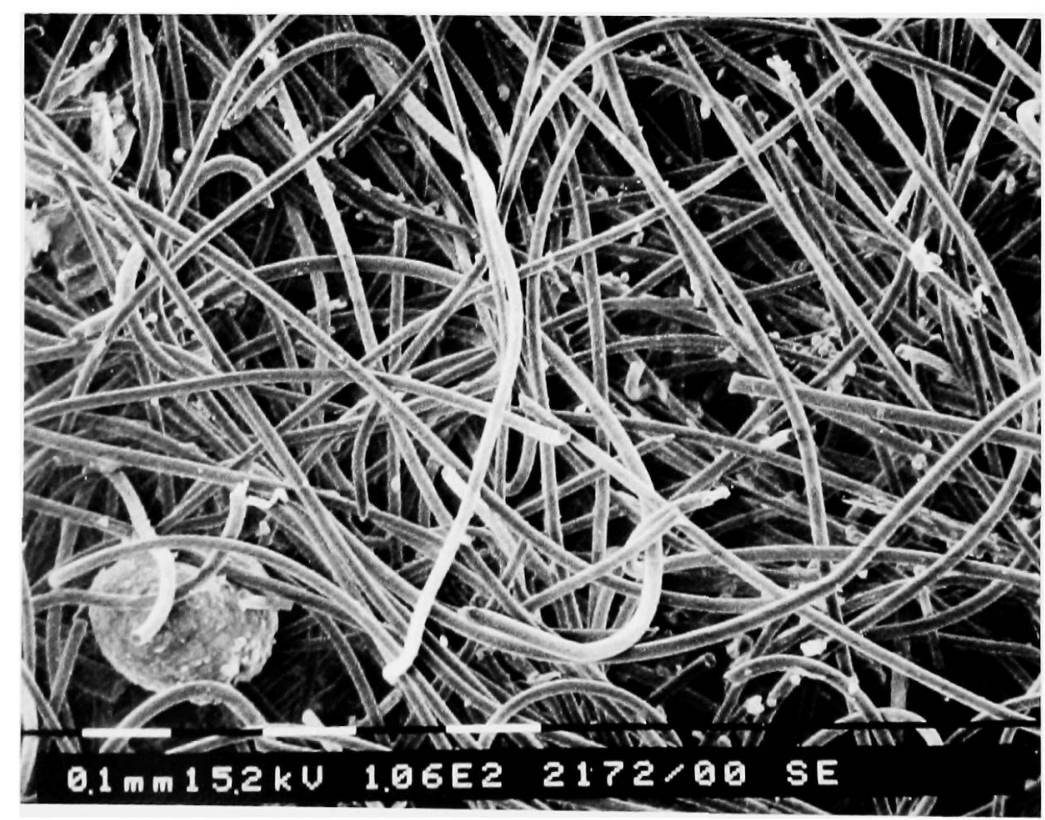

FIG. 1. Scanning electron micrograph of PGA stirred with aortic endothelial cells for $20 \mathrm{~h}$. Similar specimens are implanted at this time. $(\times 106)$ 


\section{INCREASED VASCULARIZATION AND HETEROGENEITY OF VASCULAR STRUCTURES}

\section{Histology}

There were no significant differences in implanted cell growth over time between PGA matrices with aortic smooth muscle cells or skeletal muscle cells. A foreign body, multinucleated giant cell reaction occurred in the presence of polymer fragments and was a consistent observation with each of the PGA matrices. Interestingly, the giant cell reaction was grossly less within matrices which had been stirred with cells prior to implantation. A substantial capillary network developed early (well defined at 1 week) within the fibrous capsule surrounding all the polymers. Vascularization proceeded from this network into the interstices of the polymers with capillaries appearing through the 3-mm-thick matrices by 3 to 4 weeks. At this time, all of the PGA meshes also showed evidence of growth of the added cells within the matrix. Host cell ingrowth of the matrices was variable but generally occurred at a rate of $1.0 \mathrm{~mm} /$ week on the side of the matrix placed against the chest wall. Cellular ingrowth from the skin side into the matrix was more variable and tended to be less $(0.5$ to $1.0 \mathrm{~mm} /$ week $)$. The most consistent ingrowth occurred from surfaces that made direct contact with muscle. The cellular ingrowth was comprised primarily of fibroblasts, macrophages, giant cells, and capillaries. There were no major differences in vascularization or host cell ingrowth among PGA polymers without cells or with aortic smooth muscle cells or with skeletal muscle cells. Therefore, examples of the aortic smooth muscle cell and the skeletal muscle cell data are not shown. The implanted muscle cells showed cellular growth with little organization. Both skeletal and smooth muscle cells were present within the matrices as scattered cells and as clumps. Bands of collagen deposition, as demonstrated by the Masson's trichrome stain, we seen concomitantly with the host cellular ingrowth. The presence of capillaries was demonstrated by individual factor VIII positive cells, often in a circular configuration. This was further substantiated by the presence of erythrocytes within the lumen. Occasionally, factor VIII positive, capillary-like structures were encountered that were devoid of erythrocytes but contained numerous lymphocytes. These were commonly seen in matrices with aortic endothelial cells, rarely in matrices with skeletal or smooth muscle cells, and never in matrices without added cells. These are hereafter designated "lymphatic-like structures."

Matrices containing endothelial cells demonstrated organized and scattered individual endothelial cells growing within the matrix (Figs. 2,3). Compared to the matrices alone and matrices containing control cells, the PGA with endothelial cells demonstrated increased numbers of capillaries (Figs. 4,5), particularly at week 1. There were also increased numbers of lymphatic-like structures (Fig. 6), and numerous unusual heterogeneous vascular structures. These structures which stained positive for factor VIII include: a) large
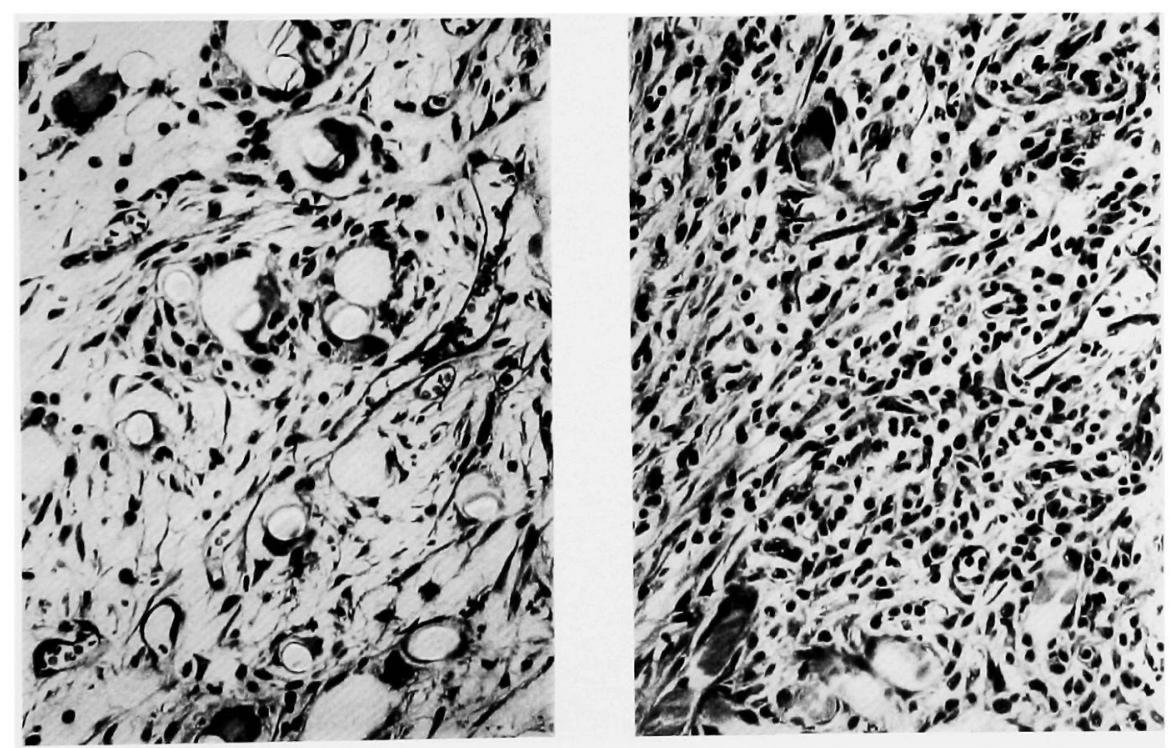

FIG. 2. Histology of PGA with (right) and without (left) aortic endothelial cells, harvested at 1 week and stained with anti-factor VIII with hematoxylin counter stain. $(\times 210)$ 


\section{HOLDER ET AL.}
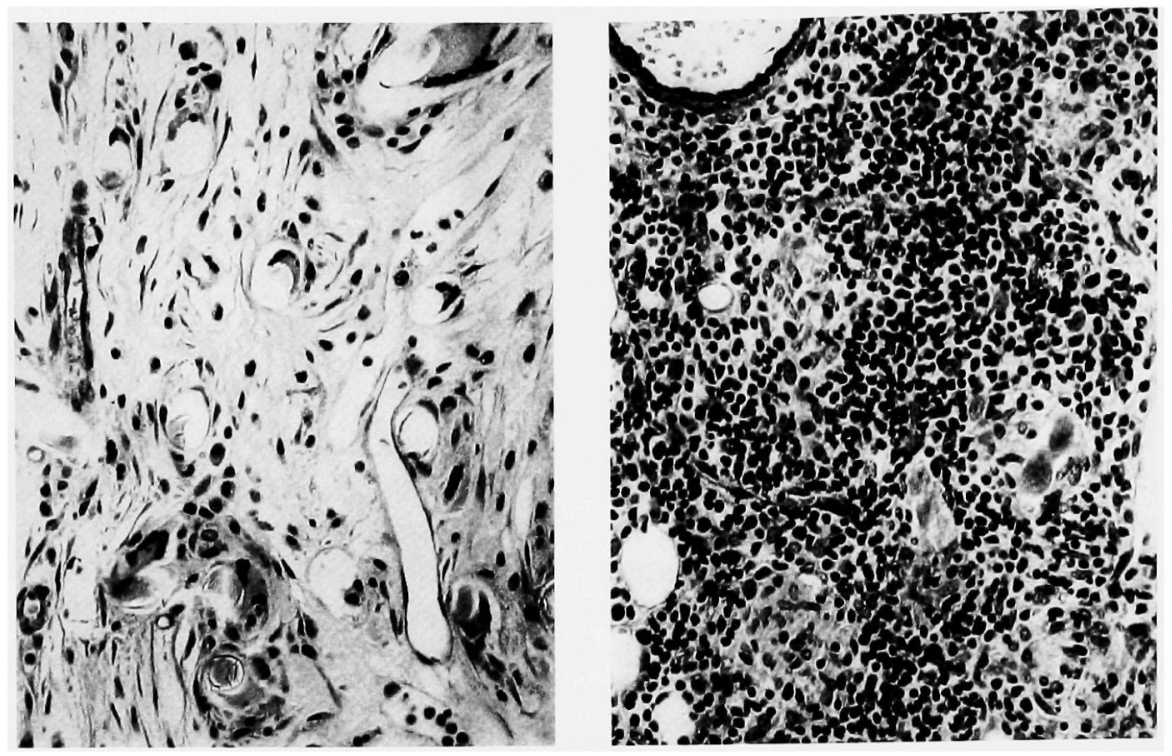

FIG. 3. Histology of PGA with and without aortic endothelial cells, harvested at 3 weeks and stained with antifactor VIII with hematoxylin counter stain. $(\times 210)$

parallel arrays of capillaries (Fig. 7), b) large, thin, single-cell-thick tubular sinusoidal structures (Fig. 8), and c) complex membranous and layered structures (Fig. 9). The heterogeneous vascular structures contained erythrocytes and were consistently observed in the endothelial cell-containing polymers and not in the other groups. The heterogeneous vascular structures were most numerous at weeks 1 and 3 , and less numerous, but still present, by week 4 . The large parallel arrays of capillaries were most frequently seen within the matrix adjacent to the edge near the capsule. These varied from 4 or 5 to as many as 30 parallel capillaries, and were interconnected with other capillaries within the matrix and capsular capillaries.

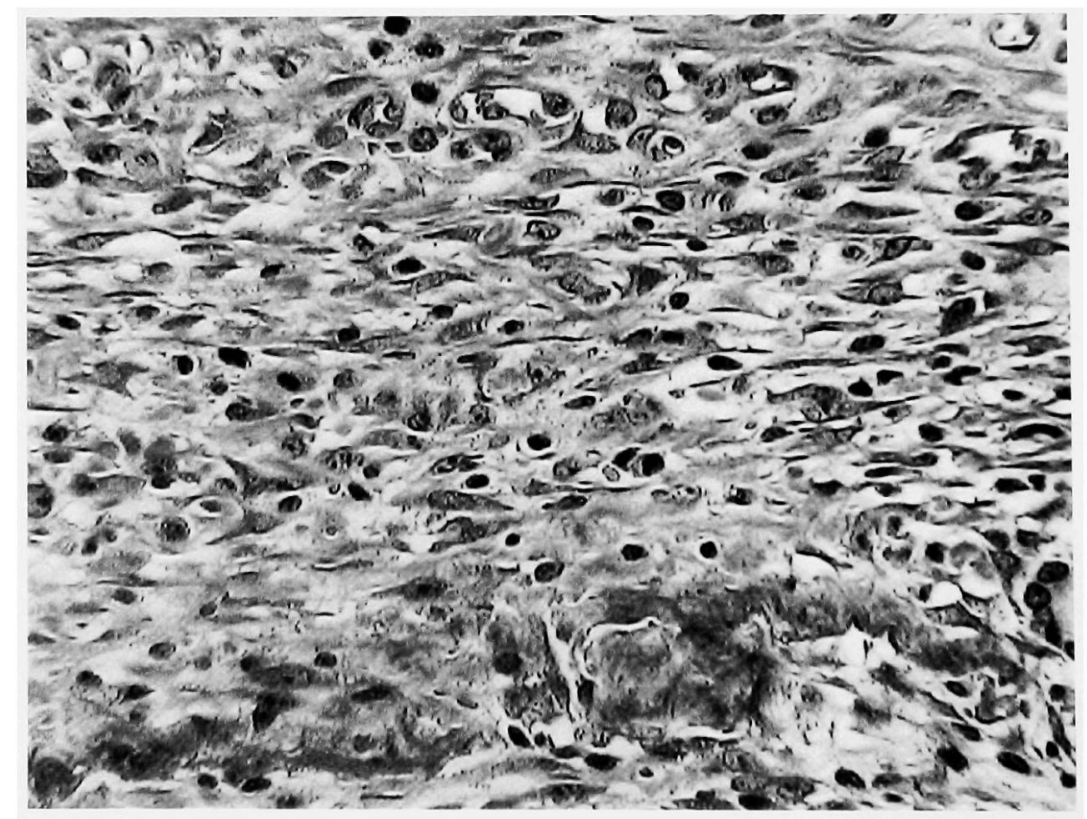

FIG. 4. Histology of PGA containing aortic endothelial cells showing large numbers of capillaries that are typically noted that are grossly increased from controls. ( 2 weeks) $(\times 485)$ 


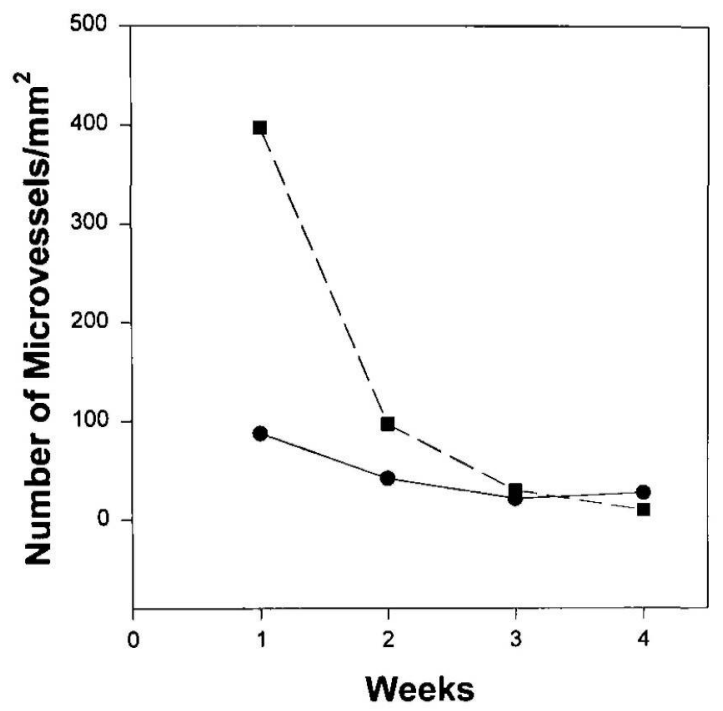

FIG. 5. Comparison of capillary counts of implanted matrices with aortic endothelial cells ( $\mathbf{\square}$ ) or aortic smooth muscle cells (-) for each of 4 weeks after implantation.

These capillaries appeared normal in size, with their diameter often completely filled with a single erythrocyte. The large sinusoidal tubular structures were composed of a single cell layer that was identical to the cells of smaller capillaries. The size of these structures varied greatly and included large tubular structures up to 20 times larger in diameter than typical capillaries. The layered complex structures were the most unusual features encountered. These most often occurred within the matrix at the periphery or at the edge of a matrix in a small fracture or space. In some structures resembling lacunae or sinuses, no cellular elements could be defined within the wall, and the wall appeared to be composed of a filamentous material that stained with anti-factor VIII. Blood cells were present within most of these structures and, if viewed immediately before fixation, these matrices had a bloody appearance. Other structures demonstrated some

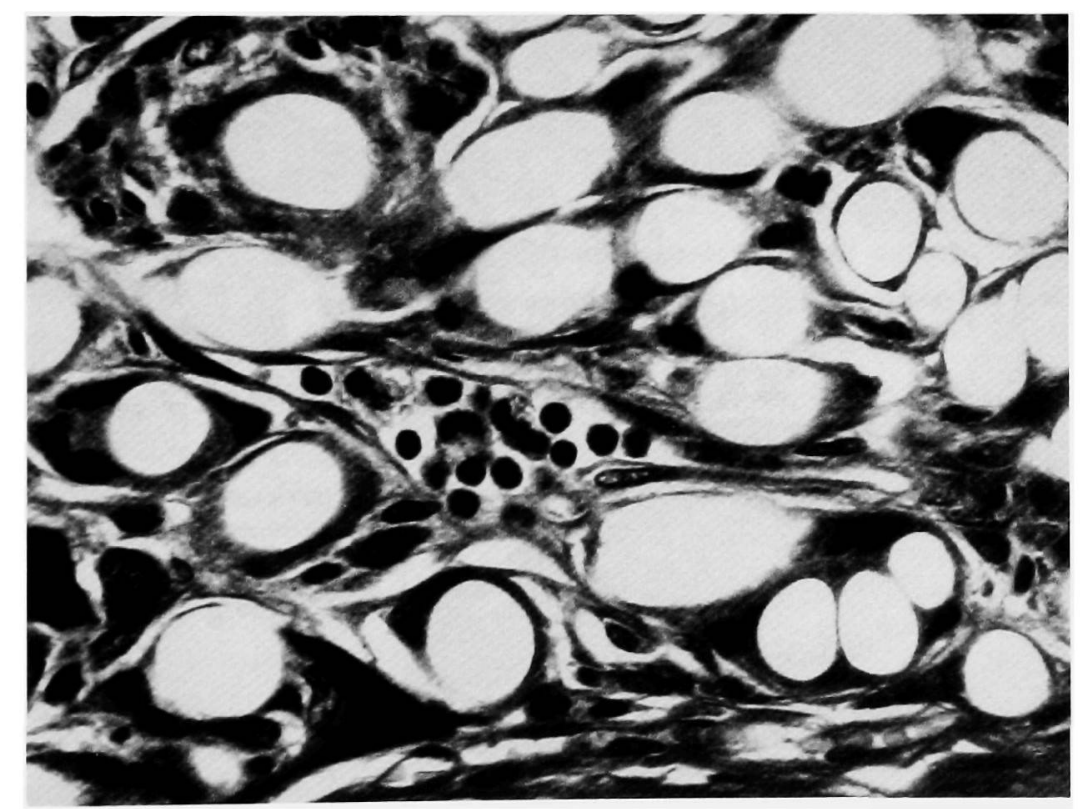

FIG. 6. Histology of PGA containing aortic endothelial cells showing lymphatic-like structure with numerous lymphocytes and no erythrocytes. $(2$ weeks $)(\times 500)$ 


\section{HOLDER ET AL.}

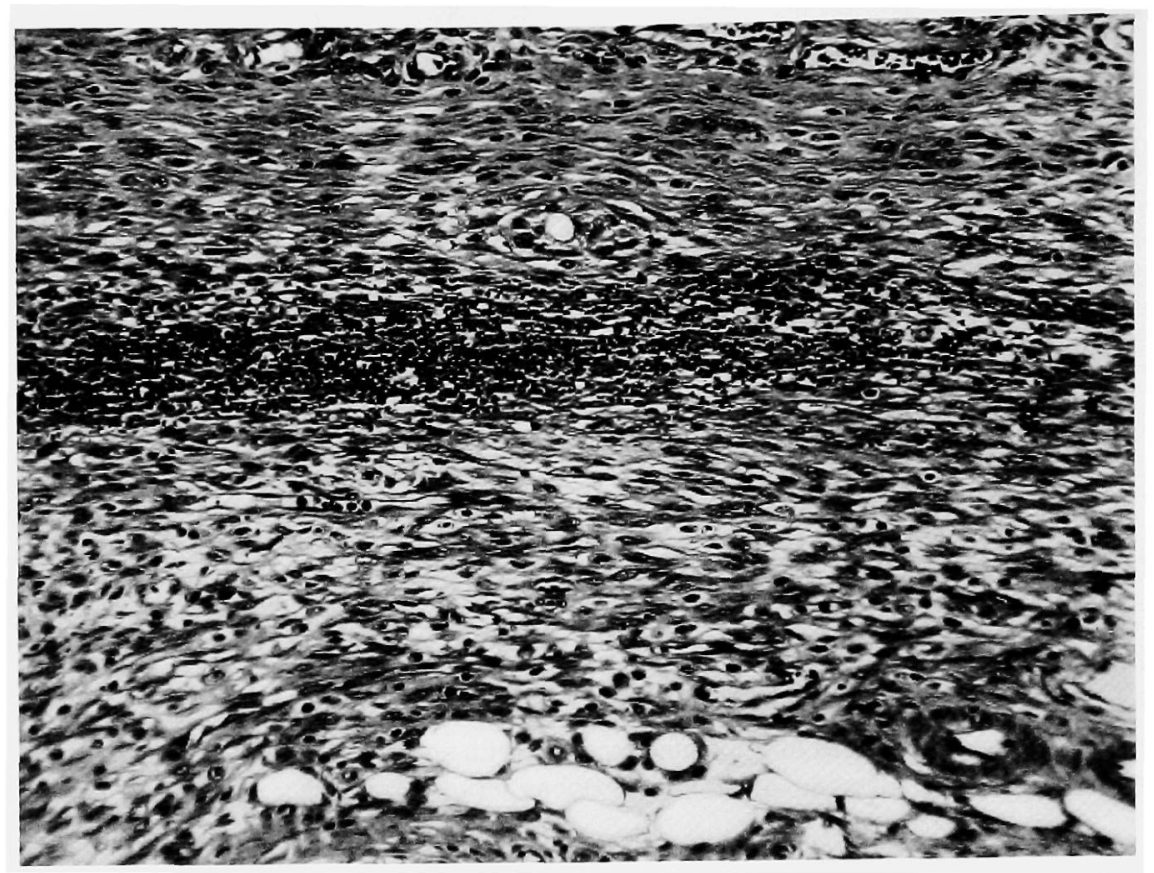

FIG. 7. Histology of PGA containing aortic endothelial cells showing large parallel array of capillaries. (2 weeks) $(\times 240)$

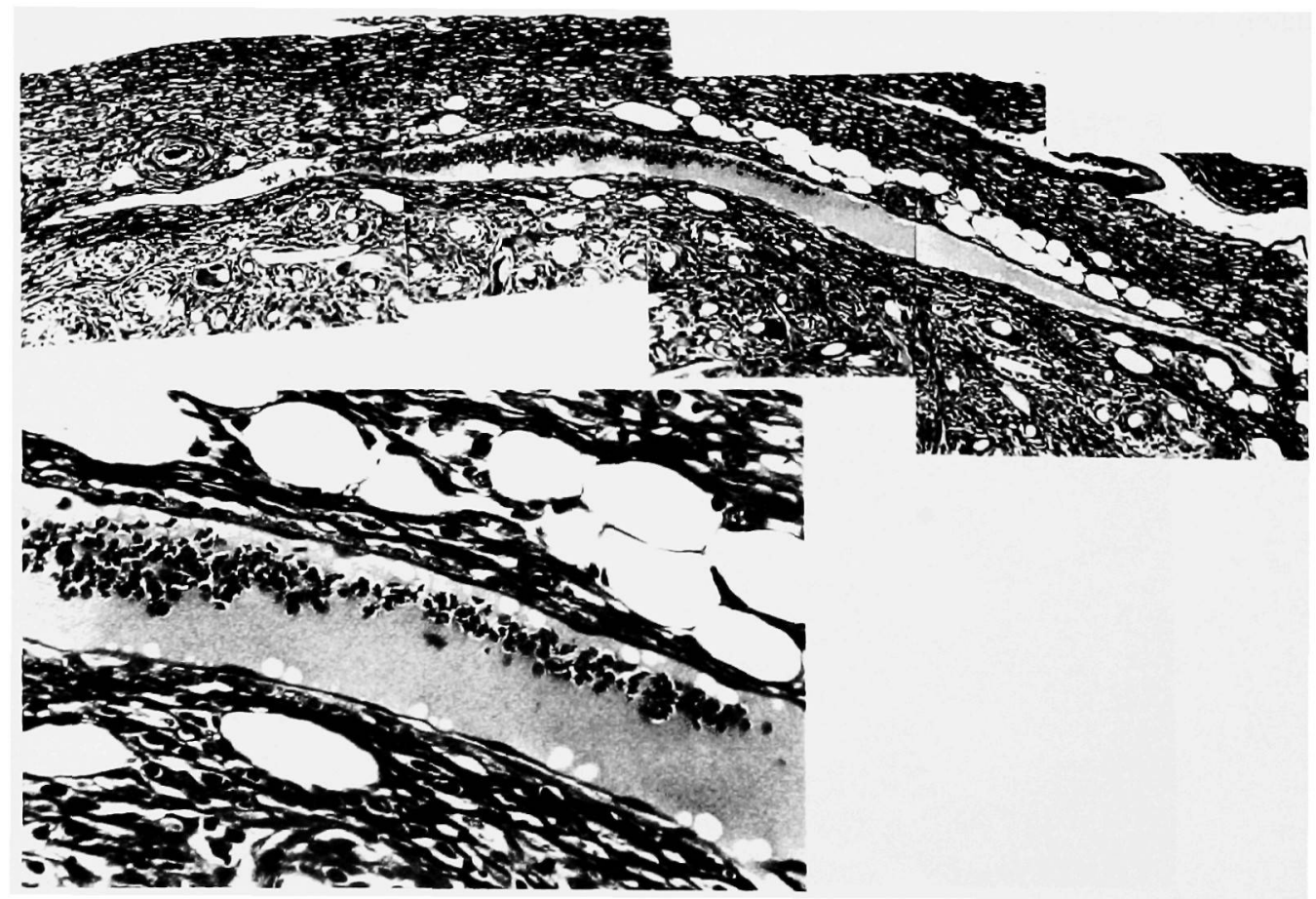

FIG. 8. Histology of PGA containing aortic endothelial cells showing a large blood-containing sinusoidal vessel (week 3). 


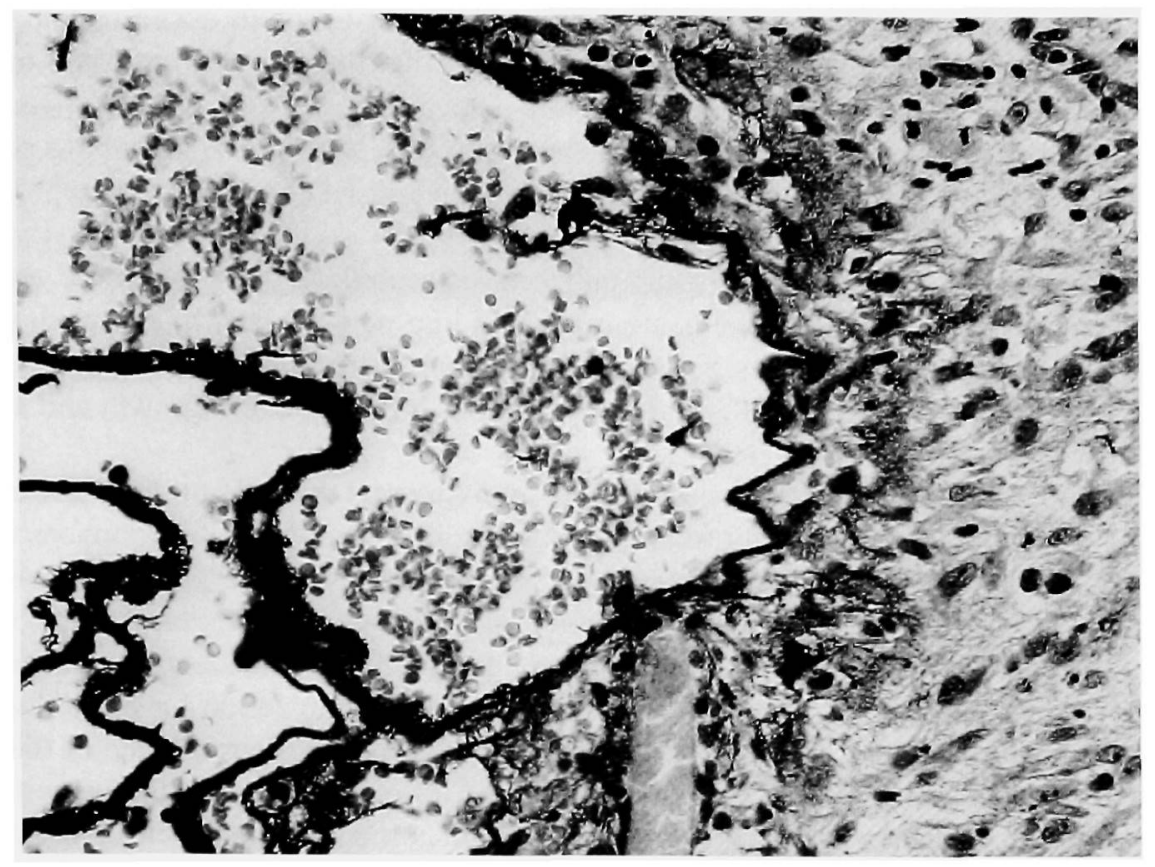

FIG. 9. Histology of PGA containing aortic endothelial cells with blood-containing complex membranous structure. Stained with anti-factor VIII and hematoxylin counterstain. (week 3$)(\times 485)$

evidence of organization with a second thicker layer with the appearance of an internal elastic lamina present below the filamentous thin material. Table 1 outlines the findings with the different cell types in the PGA matrix.

\section{DISCUSSION}

The data demonstrate a definite vascularization-enhancing effect of aortic endothelial cells added to implanted PGA polymers during a period of 4 weeks of observations. There is a gross increase in capillary development throughout the matrices along with the development of some interesting structures that appear to be precursors of multi-layered vessels, possibly arteries/arterioles or veins/venules. This observation has not previously been reported by other authors. Researchers conducting this study have had considerable experience evaluating a variety of absorbable polymers implanted with and without various cells into rats. The observation of enhanced vascularization has not been made with multiple other cell types with polymers including PGA and poly(lactic) acid (PLLA) sponges. The authors have, however, also observed the

Table 1. Structures Demonstrated in PGa Matrix Implanted 1 to 4 Weeks, With and Wrthout Cells

\begin{tabular}{lcccc}
\hline & $P G A$ alone & $P G A+A E$ & $P G A+$ SmMC & $P G A+S k M C$ \\
\hline Capillaries & + & + & + & + \\
Lymphatic structures & - & + & + & + \\
Parallel capillary arrays & - & + & - & - \\
Large thin-walled vessels & - & + & - & - \\
Layered complex structures & - & + & - \\
\hline
\end{tabular}

PGA = poly (glycolic) acid polymer; $\mathrm{AE}=$ aortic endothelial cells; SmMC $=$ smooth muscle cells; SkMC $=$ skeletal muscle cells. 


\section{HOLDER ET AL.}

large parallel capillary arrays and layered complex structures in PLLA with aortic endothelial cells implanted 1 to 4 weeks (unpublished). This observation suggests that the effect is unrelated to the polymer type but is related more specifically to the cell type.

The stirred method of loading cells onto polymers has been observed by the authors to produce excellent cell adhesion throughout the entire polymer. This technique will be compared with other methods in a future publication.

There are several possible mechanisms for the enhanced vascularization of the aortic endothelial cell loaded matrices: a) the added endothelial cells are organized into new vessels, b) endothelial cells do not grow to produce new vessels but provide signals (growth factors, extracellular matrix) for the ingrowth of host vessels, c) added endothelial cells both produce signals for host vascular ingrowth and also grow into vessels that mesh with ingrowing host vessels.

Some non-organized endothelial cells persist fairly evenly scattered throughout the matrices through the 4 weeks of observation. While it is difficult to know with certainty what ultimately happens to these cells, there are several possibilities: a) they persist as non-organized endothelial cells, b) they eventually are organized into vascular structures, c) they are incorporated into ingrowing host vascular structures, d) they dedifferentiate into fibroblast-like cells, or e) they eventually die. These cells have been observed to persist and growth within the matrices by simple expansion with little organization for up to 8 weeks in vitro (unpublished). Longer-term studies with specifically labeled cells may explain the fate of these cells.

The addition of aortic endothelial cells greatly enhances the development of capillaries within the first 2 weeks as compared with controls without cells or polymers with aortic smooth muscle cells or skeletal muscle cells (Fig. 5). The number of capillaries rapidly diminishes, however. From these histological observations, there appears to be a major change in vessel formation during this time to produce new structures. This can occur as a result of vascular splitting (intussusceptive growth), vascular fusion, and vascular regression. The large sinuses are similar to structures in the liver and spleen, and some of the vessels resemble irregular vessels in recanalized thrombus.

Since the aortic endothelial cells do not appear to organize into any tubular structures prior to implantation (Fig. 1), it appears that the signals for organization come from the host, perhaps in response to the foreign body reaction produced by the matrix. Several authors have reported that macrophages and giant cells produce factors that induce angiogenesis in response to injury and other stimuli, particularly some types of cancer. ${ }^{22}$ Angiogenesis is normally a multistep process to form capillaries from existing vessels. This process includes endothelial cell proliferation and migration and organization into new capillaries. Multiple factors are known to stimulate angiogenesis primarily by direct effects on capillary endothelial cells, including vascular endothelial cell growth factor (VEGF), basic fibroblastic growth factor (BFGF), epidermal growth factor (EGF), platelet derived growth factor (PDGF), tumor necrosis factor- $\alpha$ (TNF- $\alpha$ ) insulin-like growth factor-l, and hepatocyte growth factor. ${ }^{23}$ Several of these factors are known to be secreted by monocytes/macrophages (EGF, ${ }^{24}$ TNF- $\alpha,{ }^{25}$ VEGF, and $\mathrm{BFGF}^{26}$ ), particularly in cancer patients. Also, macrophages in the presence of lactide-glycolide copolymers have been shown to produce BFGF. ${ }^{27}$ These observations demonstrate a possible role of monocytes/macrophages in the production of signals to induce polymer vascularization. However, we have noted that PGA and PLLA loaded with cells using the stirred method have grossly fewer giant cells than polymers without added cells or polymers on which cells have been dropped prior to implantation. This suggests that giant cells play less of a role in the matrices seeded with aortic endothelial cells.

\section{CONCLUSIONS}

The production of thicker tissue constructs is perhaps the greatest difficulty to be overcome in tissue engineering before fully functional major tissues and organs can be produced. A first step in this direction is to increase the amount of early vascularization and the rate of overall vascularization. This would assure better perfusion of implanted cells, permit more of these cells to proliferate, and allow for the development of a larger organ or tissue. It appears that the addition of vascular endothelial cells may be one of the simplest means to achieve this goal. 


\section{INCREASED VASCULARIZATION AND HETEROGENEITY OF VASCULAR STRUCTURES}

Matrices containing endothelial cells demonstrated organized and unorganized endothelial cells within the matrix, increased numbers of capillaries, increased numbers of lymphatic-like structures, and numerous unusual heterogeneous vascular structures, which were blood-containing and factor VIII positive, including: a) large parallel arrays of capillaries, b) large, thin, sinusoidal vascular structures, and c) layered complex structures. These observations suggest that the addition of aortic endothelial cells to PGA matrices enhances vascularization of the matrices over the 4-week period observed in this experiment. This observation suggests that the addition of vascular endothelial cells to tissue-engineered constructs may facilitate the development of thicker constructs by permitting earlier and possibly more rapid vascularization of implanted cell/polymer matrices.

\section{ACKNOWLEDGMENTS}

This work was supported by funding from The Carolinas HealthCare System, Carolina Tissue Development Partners, and ReproGenesis Corporation. The technical assistance of Brian Gordon, D.V.M., Audrey Stasky, Donna Crawford, and the vivarium staff is appreciated.

\section{REFERENCES}

1. Data derived from American Heart Association, American Lung Foundation, Diabetes Association, American Kidney Foundation, Muscular Dystrophy Association and the National Institutes of Health.

2. Belle, S.H., Beringer, K.C., and Detre, K.M. Liver transplantation in the United States: Results from the National Pitt-UNOS Liver Transplantation Registry. United Network for Organ Sharing Clin. Transpl. 8, 19, 1994.

3. Freundlich, B., Altman, C., Snadorfi, N., Greenberg, M., and Tomaszewski, J. A profile of symptomatic patients with silicone breast implants: A Sjogrens-like syndrome. Semin. Arthritis Rheum. 24 (1 Suppl 1), 44, 1994.

4. Hubbell, J.A. Biomaterials in tissue engineering. Biotechnology 13, 565, 1995.

5. Freed, L.E., Vunjak-Novakovic, G., Biron, R.J., et al. Biodegradable polymer scaffolds for tissue engineering. Biotechnology 12,689, 1994.

6. Murphy, G.F., Orgill, D.P., and Yannas, I.V. Partial dermal regeneration is induced by biodegradable collagenglycosaminoglycan grafts. Lab. Invest. 63, 305, 1990.

7. Hansbrough, J.F., Cooper, S.L., and Greenleaf, G. Evaluation of a biodegradable matrix containing cultured human fibroblasts as a dermal replacement beneath meshed split-thickness skin grafts. Surgery 111, 438, 1992.

8. Mooney, D.J., Johnson, L., Cima, L., Vacanti, J.P., and Langer, R. Principles of tissue engineering and reconstruction using polymer-cell constructs. In Cima, L.G., Ron, E.S., eds. Tissue Inducing Biomaterials. Materials Research Society Symposium Proceedings, Pittsburgh, PA. Materials Research Society. December, 252, 199, 1992.

9. Uyama, S.. Takeda, T., and Vacanti, J.P. Delivery of a whole liver equivalent hepatic mass using polymer devices and hepatotrophic stimulation. Transplantation 55,(4), 932, 1993.

10. Fontaine, M.J., Hanson, L.K., Thompson, S., et al. Transplantation of genetically altered hepatocytes using cellpolymer constructs leads to sustained human growth secretion in vivo. Transplant Proc. 25, 1002, 1993.

11. Freed, L.E., Marquis, J.C.. Nohria, A., et al. Neocartilage formation in vitro and in vivo using cells cultured on synthetic biodegradable polymers. J. Biomed. Mat. Res. 27, 11, 1993.

12. Vacanti, C.A., Langer, R., Schloo, B., et al. Synthetic polymers seeded with chondrocytes provide a template for new cartilage formation. J. Plastic Reconstr. Surg. 88, 733, 1991.

13. Vacanti, C.A., Kim, W., Upton, J., et al. Tissue engineered growth of bone and cartilage. Transpl. Proc. 25, 1019, 1993.

14. Kim, W., Vacanti, J.P., Upton, J., et al. The repair of cranial defects in rats with cartilage grown from chondrocytes on synthetic polymer templates. Presented at the 39th Annual Meeting of the Orthopaedic Research Society, February 1993.

15. Atala, A., Vacanti, J.P., Peters, C.A., et al. Formation of urothelial structures in vivo from disassociated cells attached to biodegradable polymer scaffolds in vitro. J. Urol. 148, 658, 1992.

16. Organ, G.M., Mooney, D.J., Hansen, L.K., et al. Transplantation of enterocytes utilizing polymer-cell constructs to produce neointestine. Transpl. Proc. 24, 3009, 1992.

17. Organ, G.M., Mooney, D.J., Hansen, L.K., et al. Enterocyte transplantation using cell polymer devices causes intestinal epithelial lined tube formation. Transpl. Proc. 25, 998, 1993. 


\section{HOLDER ET AL.}

18. Vert, M., and Li, S.M., Bioresorbability and biocompatibility of aliphatic polyesters. J. Mater. Sci. Mater. Med. 3, 432, 1992.

19. Hoffman, K.R., and Casy, D.J. Effect of carboxyl end groups on hydrolysis of polyglycolic acid. J. Polym. Sci. Polym. Chem. Ed. 23, 1939, 1985.

20. Miller, R.A., Brady, J.M., and Cutright, D.E. Degradation rates of oral resorbable implants (polylactates and polyglycolates): Rate modification with changes in PLA/PGA copolymer ratios. J. Biomed. Mater. Res. 11, $711,1977$.

21. Weidner, N., Semple, J.P., Welch, W.R., Folkman, J. Tumor angiogenesis and metastasis: Correlation in invasive breast carcinoma. N. Engl. J. Med. 324, 108, 1991.

22. Leek, R.D., Lewis, C.E., Whitehouse, R., Greenall, M., Clarke, J., and Harris, A.L. Association of macrophage infiltration with angiogenesis and prognosis in invasive breast carcinoma. Cancer Res. 56, 4625, 1996.

23. Leek, R.D., Harris, A.L., and Lewis, C.E. Cytokine networks in solid human tumors: Regulation of angiogenesis. J. Leukoc. Biol. 56, 423, 1994.

24. O’Sullivan, C., Lewis, C.E., Harris, A., and McGee, J.O. Secretion of epidermal growth factor by macrophages associated with breast carcinoma. Lancet 342, 148, 1993.

25. Pusztai, L., Clover, L.M., Cooper, K., Starkey, P.M., Lewis, C.E., and McGee, J.O. Expression of tumor necrosis factor alpha and its receptors in carcinoma of the breast. Br. J. Cancer 70, 289, 1994.

26. Lewis, C.E., Leek, R., Harris, A.L., and McGee, J.O. Cytokine regulation of angiogenesis in breast cancer: The role of tumor-associated macrophages. J. Leukoc. Biol. 57, 747, 1995.

27. Greisler, H.P., Gosselin, C., Ren, D., Kang, S.S., and Kim, D.U. Biointeractive polymers and tissue engineered blood vessels. Biomaterials 17, 329, 1996.

Address reprint requests to:

Walter D. Holder, Jr., M.D.

Department of General Surgery Research

Carolinas Medical Center

Box 32861

Charlotte, NC 28232-2861 


\section{This article has been cited by:}

1. A. L. Sieminski, C. E. Semino, H. Gong, R. D. Kamm. 2008. Primary sequence of ionic self-assembling peptide gels affects endothelial cell adhesion and capillary morphogenesis. Journal of Biomedical Materials Research Part A 87A:2, 494-504. [CrossRef]

2. Haifei Shi, Chunmao Han, Zhengwei Mao, Lie Ma, Changyou Gao . 2008. Enhanced Angiogenesis in Porous Collagen-Chitosan Scaffolds Loaded with AngiogeninEnhanced Angiogenesis in Porous Collagen-Chitosan Scaffolds Loaded with Angiogenin. Tissue Engineering Part A 14:11, 1775-1785. [Abstract] [PDF] [PDF Plus]

3. E. Jabbarzadeh, T. Starnes, Y. M. Khan, T. Jiang, A. J. Wirtel, M. Deng, Q. Lv, L. S. Nair, S. B. Doty, C. T. Laurencin. 2008. Induction of angiogenesis in tissue-engineered scaffolds designed for bone repair: A combined gene therapy-cell transplantation approach. Proceedings of the National Academy of Sciences 105:32, 11099-11104. [CrossRef]

4. Saejeong Kim , Horst von Recum . 2008. Endothelial Stem Cells and Precursors for Tissue Engineering: Cell Source, Differentiation, Selection, and ApplicationEndothelial Stem Cells and Precursors for Tissue Engineering: Cell Source, Differentiation, Selection, and Application. Tissue Engineering Part B: Reviews 14:1, 133-147. [Abstract] [PDF] [PDF Plus]

5. Ehsan Jabbarzadeh, Tao Jiang, Meng Deng, Lakshmi S. Nair, Yusuf M. Khan, Cato T. Laurencin. 2008. Human endothelial cell growth and phenotypic expression on three dimensional poly(lactide-co-glycolide) sintered microsphere scaffolds for bone tissue engineering. Biotechnology and Bioengineering 98:5, 1094-1102. [CrossRef]

6. A. L. Sieminski, A. S. Was, G. Kim, H. Gong, R. D. Kamm. 2007. The Stiffness of Three-dimensional Ionic Self-assembling Peptide Gels Affects the Extent of Capillary-like Network Formation. Cell Biochemistry and Biophysics 49:2, 73-83. [CrossRef]

7. Matthias W. Laschke, Yves Harder, Michaela Amon, Ivan Martin, Jian Farhadi, Andrej Ring, Nestor Torio-Padron, René Schramm, Martin Rücker, Dominic Junker, Jörg M. Hä, Carlos Carvalho, Michael Heberer, Günter Germann, Brigitte Vollmar, Michael D. Menger. 2006. Angiogenesis in Tissue Engineering: Breathing Life into Constructed Tissue Substitutes. Tissue Engineering, ahead of print060913044658052. [CrossRef]

8. Cleo S.N. Choong, Dietmar W. Hutmacher, James T. Triffitt. 2006. Co-culture of Bone Marrow Fibroblasts and Endothelial Cells on Modified Polycaprolactone Substrates for Enhanced Potentials in Bone Tissue Engineering. Tissue Engineering, ahead of print060913044658009. [CrossRef]

9. Cleo S.N. Choong, Dietmar W. Hutmacher, James T. Triffitt . 2006. Co-culture of Bone Marrow Fibroblasts and Endothelial Cells on Modified Polycaprolactone Substrates for Enhanced Potentials in Bone Tissue EngineeringCo-culture of Bone Marrow Fibroblasts and Endothelial Cells on Modified Polycaprolactone Substrates for Enhanced Potentials in Bone Tissue Engineering. Tissue Engineering 12:9, 2521-2531. [Abstract] [PDF] [PDF Plus]

10. Matthias W. Laschke, Yves Harder, Michaela Amon, Ivan Martin, Jian Farhadi, Andrej Ring, Nestor Torio-Padron , René Schramm, Martin Rücker, Dominic Junker , Jörg M. Häufel, Carlos Carvalho , Michael Heberer, Günter Germann , Brigitte Vollmar, Michael D. Menger . 2006. Angiogenesis in Tissue Engineering: Breathing Life into Constructed Tissue SubstitutesAngiogenesis in Tissue Engineering: Breathing Life into Constructed Tissue Substitutes. Tissue Engineering 12:8, 2093-2104. [Abstract] [PDF] [PDF Plus]

11. A.L. Sieminski , R.P. Hebbel , K.J. Gooch . 2005. Improved Microvascular Network in Vitro by Human Blood Outgrowth Endothelial Cells Relative to Vessel-Derived Endothelial CellsImproved Microvascular Network in Vitro by Human Blood Outgrowth Endothelial Cells Relative to Vessel-Derived Endothelial Cells. Tissue Engineering 11:9-10, 1332-1345. [Abstract] [PDF] [PDF Plus]

12. Ravi K. Birla , Gregory H. Borschel, Robert G. Dennis, David L. Brown . 2005. Myocardial Engineering in Vivo: Formation and Characterization of Contractile, Vascularized Three-Dimensional Cardiac TissueMyocardial Engineering in Vivo: Formation and Characterization of Contractile, Vascularized Three-Dimensional Cardiac Tissue. Tissue Engineering 11:5-6, 803-813. [Abstract] [PDF] [PDF Plus]

13. Eric M. Brey, Shiri Uriel, Howard P. Greisler, Larry V. McIntire . 2005. Therapeutic Neovascularization: Contributions from BioengineeringTherapeutic Neovascularization: Contributions from Bioengineering. Tissue Engineering 11:3-4, 567-584. [Abstract] [PDF] [PDF Plus]

14. Gregory H. Borschel, Robert G. Dennis, William M. Kuzon. 2004. Contractile Skeletal Muscle Tissue-Engineered on an Acellular Scaffold. Plastic and Reconstructive Surgery 113:2, 595-602. [CrossRef]

15. K. J. L. Burg, M. Delnomdedieu, R. J. Beiler, C. R. Culberson, K. G. Greene, C. R. Halberstadt, W. D. Holder, A. B. Loebsack, W. D. Roland, G. A. Johnson. 2002. Application of magnetic resonance microscopy to tissue engineering: A polylactide model. Journal of Biomedical Materials Research 61:3, 380-390. [CrossRef]

16. K. J. L. Burg, W. D. Holder, C. R. Culberson, R. J. Beiler, K. G. Greene, A. B. Loebsack, W. D. Roland, P. Eiselt, D. J. Mooney, C. R. Halberstadt. 2000. Comparative study of seeding methods for three-dimensional polymeric scaffolds. Journal of Biomedical Materials Research 51:4, 642-649. [CrossRef] 
17. Anna B. Loebsack, Craig R. Halberstadt, Walter D. Holder, Catherine R. Culberson, Rudolph J. Beiler, Kim G. Greene, Wendy D. Roland, Karen J.L. Burg. 1999. The development of an embedding technique for polylactide sponges. Journal of Biomedical Materials Research 48:4, 504-510. [CrossRef] 